\title{
Winter profile of plasma sex steroid levels in free-living male western diamond-backed rattlesnakes, Crotalus atrox (Serpentes: Viperidae)
}

\author{
Gordon W. Schuett ，Roger A. Repp , Emily N. Taylor ， Dale F. DeNardo \\ Ryan L. Earley Edward A. Van Kirk William J. Murdoch
}

\begin{abstract}
Recent field studies on the reproductive ecology of western diamond-backed rattlesnakes (Crotalus atrox) from populations in southern Arizona showed significant differences in the concentration of plasma sex steroids (testosterone, T; $5 \alpha$-dihydrotestosterone, DHT; and 17 $\beta$-estradiol, E2) throughout the active season (March-October), and peak levels were coincident with the two mating periods (late summer and early spring). There is, however, no information on levels of sex steroids during winter. Similar to most snakes, hibernating individuals of $C$. atrox are typically inaccessible, but in southern Arizona, where environmental conditions are typically mild during winter, adult males frequently bask at or near the entrances of communal dens. Basking activity, therefore, offers a unique logistical opportunity to assess the complete annual profile of plasma sex steroid levels in males of a temperate reptile in nature. From November to February, we measured levels of plasma T, DHT, and E2 in adult male $C$. atrox that were located basking at communal dens. Additionally, cloacal, core body, and ambient air temperatures were obtained to investigate potential relationships between body temperatures and levels of sex steroids. Mean levels of T, DHT, and E2 were relatively high, and the concentration hierarchy was T > DHT > E2. Mean levels of T, DHT, and E2 showed no significant variation across the four months of sampling; however, E2 levels decreased progressively. In the annul cycle, sex steroid levels during winter were not basal when compared to values obtained during the active season. Mean cloacal temperatures of basking males were significantly higher than core body temperatures of non-basking males (inside dens) from November-December, and in February, which suggests that one function of winter basking is to elevate body temperatures. Steroid levels, nonetheless, were not significantly correlated with cloacal temperatures. We suggest that future field studies of male C. atrox should: (a) investigate sex steroid levels in non-basking individuals and (b) test whether elevated levels of sex steroids during winter facilitate the large increases that occur in early spring, which are coincident with the second mating season. Our findings on the reproductive biology of $C$. atrox and other viperids are discussed in the context of the associated-dissociated model of reproduction.
\end{abstract}

Keywords: Reptile; Snake; Pitviper; Hibernation; Steroid hormones; Mating season; Body temperature; Associated-dissociated reproduction

\section{Introduction}

Despite the challenges presented by field studies ... they are necessary for understanding the complex interactions between brain, hormones, and behavior in an evolutionary perspective (Fusani et al., 2005).

Field research on seasonal profiles of plasma sex steroid levels of animals is one of several approaches that provide a relevant context for investigating the complex interface between the environment and the mechanisms regulating reproduction (Costa and Sinervo, 2004; Insel and Fernald, 2004; Romero, 2002; Wallen and Schneider, 2000; Wingfield et al., 1997). These types of studies, moreover, often 
contribute important insights into the evolution of reproductive behavior, physiology, and mating systems (Drickamer and Gillie, 1998; Duvall et al, 1993; Feder et al., 2000; Shine, 2003). Despite their usefulness in establishing connections between proximate and ultimate causes, behavioral endocrinological studies conducted in nature are rare due to logistic difficulties and special issues (Fusani et al., 2005). In temperate regions, for example, many factors can impede obtaining complete annual profiles of plasma sex steroid levels; perhaps, the most obvious is the fact that most hibernating animals are inaccessible and thus cannot be processed directly. Furthermore, because hibernation in some species can last for 7-9 months (Gregory, 1982, 1984; Ultsch, 1989; Sexton et al., 1992), a substantial portion of the annual cycle is unknown. Consequently, for many taxa, we have incomplete knowledge of seasonal sex steroid levels. Deficiencies of these types are especially widespread in ectothermic vertebrates (Callard and Ho, 1980; Edwards and Jones, 2001a,b; Moore and Lindzey, 1992; Norris and Jones, 1987; Whittier and Tokarz, 1992). Subsequently, most studies reporting concentrations of plasma sex steroids in temperate reptiles during winter months involve subjects held under semi-natural (Edwards and Jones, 2001a,b; Saint Girons et al., 1993) or laboratory (Schuett et al., 1997; Zaidan et al, 2003) conditions, and only several involve subjects studied in nature (Cree et al., 1992; McPherson et al., 1982; Rooney et al., 2004; Tyrrell and Cree, 1998).

In southern regions of North America, where winter conditions often are mild, some species of reptiles show activity on warm days (Repp, 1998; Sexton et al., 1992). As a result, obtaining blood samples for endocrinological analyses is feasible. Basking behavior in western diamondbacked rattlesnakes (Crotalus atrox), for example, can occur at the entrances of communal dens during winter (Repp, 1998; Sexton et al., 1992), and individuals, mostly males, often are accessible for capture. Basking activity, therefore, provides a unique logistical opportunity to assess the complete annual profile of plasma sex steroid levels in males of a temperate reptile in nature.

Profiles of plasma sex steroids during the active season and their relation to reproduction in male and female C. atrox have been recently published. In this species, two mating seasons occur in the annual cycle - the first one occurs in late summer and autumn (late August-October), followed by hibernation (mid-November-mid-March) and the second one occurs in spring (mid-March-early-May). In this cycle, there is production of only a single litter in late summer (Schuett, 1992; Schuett et al., 2005; Taylor et al., 2004a; Taylor and DeNardo, 2005). During the active season, elevated (peak) levels of plasma testosterone (T), $5 \alpha-$ dihydrotestosterone (DHT), and 17 $\beta$-estradiol (E2) in adult males are coincident with the two mating seasons (Fig. 1); levels of T and DHT are lowest (basal) from May to June, and levels of E2 are basal from May to July (Schuett et al., 2005; Taylor et al., 2004a). Sexual behavior (e.g., courtship, coitus, male-male agonism) does not occur from mid-May to late August, but, during this period, elevated levels of
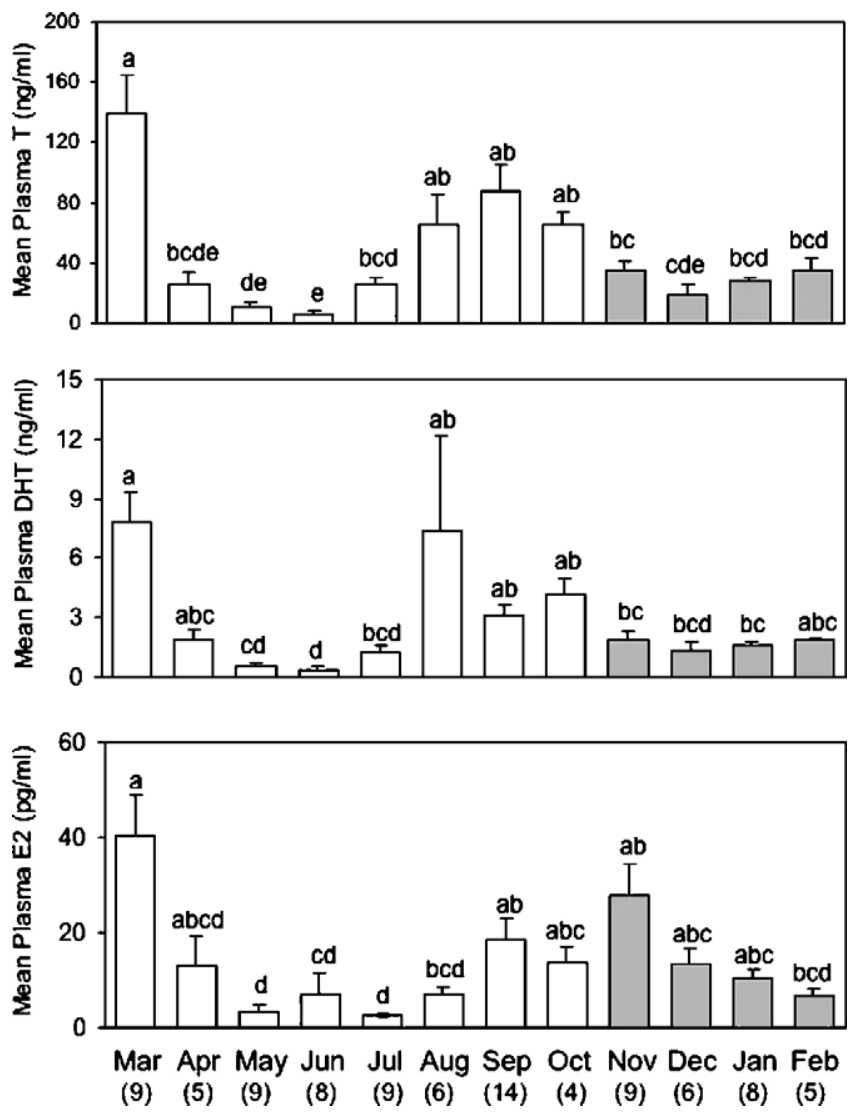

Fig. 1. Profiles of plasma sex steroid levels in adult male Crotalus atrox sampled from November to February while basking at communal dens (gray bars), and throughout the active season (white bars; modified from Schuett et al., 2005). Histogram bars represent non-adjusted, non-transformed means $( \pm 1 \mathrm{SE})$. Parenthetical values denote sample sizes for each sampling month. $\mathrm{T}=$ testosterone; $\mathrm{DHT}=5 \alpha$-dihydrotestosterone; E2 $=17 \beta$-estradiol.

plasma sex steroids are associated with spermatogenesis, which peaks in late summer (Jacob et al., 1987; Schuett, 1992; Schuett et al., 2005; Taylor et al., 2004a).

Information on levels of circulating sex steroids in wild C. atrox remains uninvestigated outside the active season. Thus, the principal goal of this study was to determine the levels of plasma T, DHT, and E2 in males during winter (November-February), and to compare those values to published levels during the active season (March-October). Specifically, we sought to establish whether levels of plasma T, DHT, and E2 in males during winter were lower than levels previously determined to be basal during the active season (Schuett et al., 2005; Taylor et al., 2004a). Basking at or near communal dens during winter is mostly limited to large adult males; consequently, we report only on them. A second related goal was to determine whether there was a relationship between sex steroid levels and body (cloacal) temperatures. We discuss the possible relationship between levels of plasma sex steroids during winter and their influence of steroid levels in spring when sexual activity occurs. A detailed analysis of winter basking and communal denning in $C$. atrox will be presented in another paper (G. Schuett and R. Repp, in preparation). 


\section{Methods}

\subsection{Study sites for sex steroid analyses}

We sampled 28 adult male $C$. atrox from eight dens located in two primary areas in southern Arizona. The northern site (Pinal County) is approximately $40 \mathrm{~km} \mathrm{SSE}$ of the city of Florence, east of Highway 79, and the southern site (Pima County) is approximately $85 \mathrm{~km} \mathrm{SSW}$ of the city of Tucson, in the vicinity of the Sierrita Mountains. Both sites are similar and designated as Sonoran Desert (Brown, 1982). Characteristic plants of the regions include creosote bush (Larrea tridentata), multiple tree species (e.g., iron wood, mesquite, palo verde), and numerous species of cactus including sahuaro (Cereus giganteus), barrel (Ferocactus wislizenii), cholla and prickly pear (Opuntia sp.). The C. atrox dens we studied were located on hillsides or in shallow arroyos, and were composed largely of metamorphic rock (e.g., granite, schist, gneiss). These communal dens are discussed in Repp (1998).

\subsection{Subject capture and processing}

Adult male subjects that we located basking at or near the entrances of communal dens were captured using conventional snake hooks and plastic grabbers. The capture events always involved 2-3 fieldworkers to expedite processing snakes and collecting body and air temperatures. The capture process, which involved grabbing a snake and placing it into a clear plastic tube (1-m length; diameter varied in size), was done gently and typically in less than $1 \mathrm{~min}$ to minimize handling stress. Once in the holding tubes, cloacal temperatures were obtained in less than 1 min using a cloacal quickreading thermometer $\left( \pm 0.5^{\circ} \mathrm{C}\right.$ ) (Miller \& Weber, Inc., Ridgewood, New York, USA). Ambient air temperatures (measured at $1 \mathrm{~m}$ above ground and in shade after a 5 -min period) were also obtained using a standard laboratory mercury thermometer $\left( \pm 1.0^{\circ} \mathrm{C}\right)$. After cloacal temperatures were obtained, blood was collected from caudal vessels using heparintreated $1-\mathrm{ml}$ tuberculin syringes fitted with $25-\mathrm{G}$ needles. From the onset of capture, blood samples were typically collected in under $5 \mathrm{~min}$, but, due to logistic difficulties, three subjects were held individually in large plastic buckets for 3-7 min before blood was collected. Based on previous work on snakes and other reptiles (e.g., Moore et al., 2000a,b; Lance et al., 2003), blood collected from all of our subjects was done in an acceptable timecourse for obtaining levels of plasma sex steroids (T, DHT, and E2) that would not be adversely affected (e.g., suppression) by handling stress.

Blood was immediately transferred from the syringe to a labeled $1.5-\mathrm{ml}$ centrifuge tube, and then placed on ice in a small cooler until centrifugation in the laboratory $(6-10 \mathrm{~h}$ later). The delay in obtaining plasma by this range of time does not affect the stability of sex steroids in C. atrox (Taylor and Schuett, 2004). Blood samples were centrifuged for $4 \mathrm{~min}$ at $6000 \mathrm{~g}$, and plasma was collected into labeled $1.5-\mathrm{ml}$ centrifuge tubes and stored frozen at $-80^{\circ} \mathrm{C}$ until radioimmunoassays of steroids could be performed ( $<6$ months).

The next procedure for each subject involved obtaining body measurements and determining sex. All methods of measurement following Taylor et al. (2004a,b). Snout-vent length (SVL), tail length (TL), body mass, and both cloacal and ambient air temperatures are presented as arithmetic means \pm 1 SE. Sex was determined using standard snake probes. Last, identification of each subject for future reference was accomplished using both long-term (PIT-tags; AVID, Inc., Norco, California, USA) and shortterm (painting proximal rattle segments, photography) methods. After processing, all subjects were released at the exact site of their capture. The period of sampling for plasma sex steroids and cloacal temperatures was from mid-November to February in 1999-2000. All sampling was conducted from 1000 to $1700 \mathrm{~h}$ to reduce possible diel effects of sex steroid levels.

\subsection{Core body temperatures of subjects utilizing radiotelemetry}

Five adult male $C$. atrox involved in another study (G. Schuett and R. Repp, unpublished) that was conducted near the present northern site
(Pinal County) were used to compare cloacal temperatures of basking individuals (1999-2000) obtained herein to core body temperatures of non-basking individuals inside dens (November-February, 2002-2003), and to core body temperatures of individuals during the active season (March-October 2003). Each of the five subjects had a single temperaturesensitive radio-transmitter (11-16 g, models AI-2T and SI-2T, Holohil Ltd., Ontario, Canada) surgically implanted intra-coelomically (for a description of the surgical methods used, see Reinert, 1992; Taylor et al., 2004a). To be consistent with the measurements of cloacal temperatures, sampling of core body temperatures from subjects with radio-transmitters was conducted from 1000 to $1700 \mathrm{~h}$. Ambient air temperatures during winter were compared between sampling years (1999-2000 vs. 2002-2003).

\subsection{Radioimmunoassay of plasma sex steroids}

We measured testosterone (T), $5 \alpha$-dihydrotestosterone (DHT), and $17 \beta$-estradiol (E2) for all collected samples by radioimmunoassay (RIA) using commercial kits with several appropriate modifications (e.g., use of snake plasma rather than rat plasma). These steroids were selected because they have known biological importance in male reptiles (Chieffi et al., 2002; Moore and Lindzey, 1992; Norris, 1997), and measured previously in male rattlesnakes and other pitvipers (Schuett et al., 1997, 2002, 2005; Taylor et al., 2004a). The RIAs of T, DHT, and E2 followed previously published procedures (Schuett et al., 1997, 2002, 2004; Taylor and Schuett, 2004), including validation (quantitative recovery and parallelism). Values for T and DHT are presented as arithmetic means $\pm 1 \mathrm{SE}(\mathrm{ng} / \mathrm{ml})$, and values for E2 are presented as arithmetic means $\pm 1 \mathrm{SE}(\mathrm{pg} / \mathrm{ml})$.

Radiolabeled $\mathrm{T}$ was purchased from Research Products International (Mount Prospect, Illinois, USA; catalog number TMM-210). The primary antibody was a gift from the laboratory of Dr. Gordon Niswender at Colorado State University. The antibody detects T, but it has a cross-reactivity of $69 \%$ with DHT (Murdoch and Dunn, 1982). Accordingly, the testosterone values obtained in this study were adjusted for the cross-reactivity of DHT by multiplying DHT concentrations by 0.69 and subtracting this value from the $\mathrm{T}$ concentrations. The RIA analytical sensitivity for $\mathrm{T}$ was $1.6 \mathrm{pg} / \mathrm{ml}$. All plasma samples $(5 \mu \mathrm{l})$ were extracted in anhydrous diethyl ether (Fisher Scientific, Chicago, IL, USA) prior to RIA. Extraction efficiency was determined by adding $\mathrm{H}^{3}$-testosterone $(25,000 \mathrm{cpm})$ to $10 \mu 1$ (twice the volume used for the assay) of snake plasma and phosphate-buffered saline, followed by incubation overnight at $4{ }^{\circ} \mathrm{C}$ and ether extraction. The quantity of $\mathrm{H}^{3}$-testosterone extracted was compared to the amount added to the sample. The extraction efficiency of radioactive $\mathrm{T}$ was $93.3 \%$. All sample values were adjusted for extraction efficiency. Cold recovery of unlabeled $\mathrm{T}$ that was added to the plasma samples previously determined to be low in $\mathrm{T}$ was $95.0 \%$. Parallelism occurred between the inhibition curves obtained with standards and serial dilutions of etherextracted plasma. Two RIAs were performed and all samples run in duplicate $(n=56)$. The intra-assay coefficients of variation $(\mathrm{CVs})$ were 9.1 and $11.1 \%$, and the inter-assay CV was $11.9 \%$.

Radiolabeled DHT and antibody were purchased from Diagnostic Systems Laboratories, Inc. (Webster, TX, USA; catalog number DSL 9600). The protocol for extraction and RIA provided by the manufacturer was followed, except that $0.20 \mathrm{ml}$ of snake plasma and $0.20 \mathrm{ml}$ of phosphate-buffered saline (with $0.1 \%$ gelatin) were used for extractions. Chromatographic steps were not required. In cases where concentrations of steroids were predicted to be high, the extract was diluted before assaying the sample. The oxidation-extraction step reduced cross-reactivity with testosterone to $0.02 \%$, and cross-reactivity with other androgens (and other steroids) was minimal or not detectable (according to the manufacturer). The RIA analytical sensitivity for DHT was $20 \mathrm{pg} / \mathrm{ml}$. Validation involved demonstrating parallelism between inhibition curves for the standards provided with the kit and serial dilutions of snake plasma. Cold recovery was not performed. A single RIA was performed and all samples run in duplicate $(n=56)$. The intra-assay $\mathrm{CV}$ was $8.9 \%$.

Radiolabelled E2, antibody, and a precipitating solution were purchased from Diagnostic Products Corporation (Los Angeles, CA, USA; catalog numbers E2D1, E2D2, and N6, respectively). Standards were prepared by serial dilutions in a stock solution of methanol. The anti-estradiol 
antibody was diluted 1:3 in phosphate-buffered saline (PBS) containing 1:400 rabbit plasma. One hundred microliters of snake plasma (with $300 \mu \mathrm{l}$ of PBS) was extracted in $5.0 \mathrm{ml}$ of anhydrous diethyl ether (Fisher Scientific, Chicago, IL, USA). After removing and saving the ether layer, the sample was heated to $90^{\circ} \mathrm{C}$ for $5 \mathrm{~min}$, and then extracted with an additional $5.0 \mathrm{ml}$ of diethyl ether. Two hundred microliters of PBS- $0.1 \%$ gelatin was added to the extract following evaporation of the ether. Extraction efficiency was determined by adding $\mathrm{H}^{3}$-estradiol $(25,000 \mathrm{cpm})$ to $100 \mu \mathrm{l}$ of snake plasma and $300 \mu \mathrm{l}$ phosphate-buffered saline, followed by incubation overnight at $4{ }^{\circ} \mathrm{C}$, and then ether extraction. The quantity of $\mathrm{H}^{3}$-estradiol extracted was compared to the amount added to the sample. Extraction recovery of $\mathrm{H}^{3}$-estradiol (New England Nuclear, Boston, MA, USA; NET-381) was 78\%. All sample values were adjusted for extraction efficiency. For the RIA, $100 \mu \mathrm{l}$ of diluted antibody, $100 \mu \mathrm{l}$ of $\mathrm{I}^{125}$-E2, and $1.0 \mathrm{ml}$ of precipitating solution were used. A 24 -h incubation $\left(4^{\circ} \mathrm{C}\right)$ period followed each step. Antibody-bound $\mathrm{I}^{125}$ was separated by centrifugation at $1800 \mathrm{~g}$. The RIA analytical sensitivity for E2 was $2 \mathrm{pg} / \mathrm{ml}$. Validation involved demonstrating that quantitative recovery of E2 added to snake plasma was $100 \%$ and that parallelism occurred between the inhibition curves for standards and dilutions of snake plasma. Two RIAs were performed and samples run in duplicate $(n=56)$. The intra-assay CVs were 7.9 and $12.5 \%$, and the inter-assay CV was $11.9 \%$.

\subsection{Statistical analyses relating to steroids and temperature data}

All data were inspected for outliers, normality (skewness and kurtosis), and equality of variance prior to performing statistical tests (Zar, 1999). Statistical analyses were performed using SAS v. 8.2 (SAS Institute, 1999) and JMP v. 5.01 (SAS Institute, 2002). Variation in mean plasma T, E2, and DHT across winter months was assessed using a general linear model analysis of covariance, with SVL as the covariate. Cloacal temperature was not used as a covariate because the assumption of independence from the main effect (month) was not upheld $\left(F_{3,24}=10.26, P=0.0002\right.$; see Results). Assumptions of the analysis of covariance were met for all steroid models (heterogeneity of slopes; T: $F_{3,20}=2.12, P=0.13$, E2: $F_{3,20}=0.57, P=0.64$, DHT: $F_{3,20}=0.33, P=0.81$; independence of SVL from month: $\left.F_{3,24}=0.87, P=0.47\right)$. Homogeneity of variance across months was demonstrated for SVL (Levene's HOV: $F_{3,24}=1.94, P=0.15$ ) and all steroids (Levene's HOV; T: $F_{3,24}=1.28, P=0.31$, E2: $F_{3,24}=0.82$, $P=0.49$, DHT: $F_{3,24}=2.27, P=0.11$ ). To achieve normality, mean levels of E2 and DHT were inverse and square root transformed, respectively; neither T nor SVL required transformation.

Analysis of variance (ANOVA) was used to compare steroid profiles of basking male $C$. atrox during the winter (present study) to male $C$. atrox during the active season (March-October, 1998 and 1999; see Schuett et al., 2005). In this analysis, all steroid values were natural-log-transformed. Methods used to conduct RIAs were similar in both studies (e.g., same laboratory, procedures, and technicians); thus, comparisons were appropriate. Repeated-measures models were not necessary for winter or winter vs. active season analyses of steroids because different subjects were sampled at each monthly interval. Measurements of steroids from the same individual are not independent; thus, each steroid was analyzed separately, and where necessary, we applied sequential Dunn-Sidak adjustments to prevent compounding of Type I error $\left[\alpha_{\text {adj }}=1-(1-\alpha)^{1 / k}\right.$ $=0.017$ for most significant model with $k=3$ steroids and the original $\alpha$-level of significance set at $P<0.05]$. Type III sum of squares and leastsquares means estimates were used to interpret variation in plasma sex steroid levels across months, but the unadjusted means are depicted in Fig. 1.

ANOVA was used to evaluate yearly variation in winter ambient temperatures (1999-2000 vs. 2002-2003); this was done to facilitate comparisons between cloacal temperatures of basking individuals (1999-2000) and core body temperatures of non-basking individuals inside dens (2002-2003). The cloacal temperatures of basking individuals were compared to core body temperatures of non-basking subjects and ambient temperatures (19992000 ) using separate ANOVAs for each winter month (November-February) and subjected to sequential Dunn-Sidak adjustments $\left(\alpha_{\text {adj }}=0.013, k=4\right.$ months). Separate monthly analyses were used because core body temperatures were repeated in individuals across all months; in contrast, ambient and cloacal temperatures were sampled from independent subjects (November-February). Cloacal and core body temperatures during winter were compared to core body temperatures of active individuals during the spring (March-June) and summer (July-October) months using ANOVA (cloacal temperatures) and repeated-measures ANOVA (core body temperatures). The relationships between cloacal temperature and SVL, and levels of T, DHT, and E2, were determined with linear regression. Recent studies on garter snakes (Thamnophis sp.) by Moore et al. (2000a,b) show that body condition (defined as the residual of the regression of body mass on SVL) can vary in the annual cycle; body condition was inversely correlated with circulating levels of corticosterone, but no relationship was uncovered with circulating levels of testosterone. Nonetheless, we determined body condition in C. atrox to assess whether there was a relationship with levels of plasma T, DHT, and E2 (see Schuett et al., 2005).

\section{Results}

\subsection{Monthly variation in plasma steroid levels and body size}

There was no significant variation in any of the plasma steroid hormone concentrations across the four winter months (November-February) in adult male C. atrox (Fig. 1). Regression showed significant relationships of $\mathrm{T}$ and DHT $\left(R^{2}=0.279\right.$, ANOVA $\left.F_{1,26}=10.05, P=0.004\right)$, and DHT and E2 $\left(R^{2}=0.165\right.$, ANOVA $\left.F_{1,26}=5.135, P=0.032\right)$, but not for T and E2 $\left(R^{2}=0.030\right.$, ANOVA $F_{1,26}=0.730$, $P=0.402$ ). Regression of SVL and body mass (dependent variable) was highly significant $\left(R^{2}=0.681\right.$, ANOVA, $\left.F_{1,26}=55.614, P<0.0001\right)$. Snout-vent length did not co-vary significantly with any of the steroids (SVL; T: $\mathrm{F}_{1,20}=0.04$, $P=0.85 ; \quad$ DHT: $\mathrm{F}_{1,20}=0.02, \quad P=0.88 ; \quad \mathrm{E} 2: \quad \mathrm{F}_{1,20}=0.52$, $P=0.58)$, and there was no significant interaction between month and SVL (T: $\mathrm{F}_{3,20}=2.12, P=0.13$; DHT: $\mathrm{F}_{3,20}=0.33$, $\left.P=0.81 ; \mathrm{E} 2: \mathrm{F}_{3,20}=0.57, P=0.64\right)$. There was no significant relationship between body condition (the residual of the regression of body mass on SVL) and plasma sex steroid levels across all winter months (November-February) (ANCOVA; body condition $\times$ winter months, all steroids: T: $\mathrm{F}_{3,20}=1.52, \quad P=0.24 ; \quad \mathrm{E} 2: \quad \mathrm{F}_{3,20}=0.05, \quad P=0.99 ; \quad$ DHT: $\mathrm{F}_{3,20}=0.27, P=0.85$ ).

Full-year analysis of sex steroid levels (March-February) demonstrated significant monthly differences for $\mathrm{T}$ $\left(F_{11,80}=11.24, P<0.0001\right)$, DHT $\left(F_{11,73}=8.54, P<0.0001\right)$, and E2 $\left(F_{11,80}=8.98, P<0.0001\right)$ (Fig. 1). Linear contrasts compared sex steroid concentrations of basking individuals during the winter (November-February) to individuals during May-June (T, DHT) and May-July (E2); these months characterize the nadir in steroid levels during the active season (Schuett et al., 2005; Taylor et al., 2004a). Concentrations of T, DHT, and E2 were significantly greater in subjects sampled during the winter than in subjects that were sampled during the nadir period (T: $F_{1,80}=23.0, P<0.0001$; DHT: $F_{1,73}=29.24, P<0.0001$; E2: $F_{1,80}=42.07, P<0.0001$ ) (Fig. 1).

\subsection{Cloacal temperature: variation with ambient temperature, month, body size, and steroid levels}

Winter ambient air temperatures of the two sampling periods (1999-2000 and 2002-2003) were not significantly 
different (year: $F_{1,40}=2.78, P=0.10$ ), and both periods showed similar monthly trends (November-February) (month $\times$ year: $F_{3,40}=2.55, P=0.07$ ). Ambient air temperatures in 1999-2000 were significantly different across winter months $\left(F_{3,24}=6.95, P=0.0016\right.$; Table 1, Fig. 2$)$. Ambient air temperatures in January were significantly lower than those in November and February $(\mathrm{SNK}, P<0.05)$ but were not significantly different from ambient air temperatures in December (SNK, $P>0.05$ ).

Cloacal temperatures of basking individuals during the winter were influenced significantly by month (ANOVA: $\left.\mathrm{F}_{4,29}=13.63, P<0.0001\right)$. Cloacal temperatures were signifi- cantly higher in November and February than in January (SNK, $P<0.05$ ), and those in December were not significantly different than any other winter month (SNK, $P>0.05$ ). Cloacal temperatures during November-January were significantly lower than core body temperatures of active animals during spring (March-June; SNK, $P<0.05$ ) and summer (July-October; SNK, $P<0.05$ ) (Table 1). Cloacal temperatures of basking individuals in February were not statistically different than core body temperatures of individuals sampled during the spring and summer (SNK, $P>0.05$ ).

During the winter of 2002-2003, core body temperatures of non-basking individuals were significantly different

Table 1

Summary of mean $( \pm 1 \mathrm{SE})$ basking (cloacal) and non-basking (core body inside den) temperatures during winter, core body temperatures during the active season (spring and summer), and ambient air temperatures during winter in adult male Crotalus atrox from southern Arizona

\begin{tabular}{llll}
\hline Temperature type & Month & Mean $\pm 1 \mathrm{SE}\left({ }^{\circ} \mathrm{C}\right)$ & Min-Max $\left({ }^{\circ} \mathrm{C}\right)$ \\
\hline Cloacal (winter, 1999-2000) & November & $25.07 \pm 0.78$ & $20.63 \pm 1.88$ \\
& December & $15.61 \pm 1.89$ & $13.0-24.0$ \\
& January & $27.36 \pm 2.13$ & $13.0-27.7$ \\
& February & $20.28 \pm 1.04$ & $13.2-32.9$ \\
Core body (winter, 2002-2003) & November & $15.74 \pm 0.50$ & $16.37 \pm 0.47$ \\
& December & $15.04 \pm 0.95$ & $14.3-23.4$ \\
& January & $26.11 \pm 0.93$ & $13.8-17.5$ \\
Ambient (winter, 1999-2000) & February & $20.67 \pm 1.79$ & $10.6-17.3$ \\
& November & $16.88 \pm 1.74$ & $23.5-31.5$ \\
& December & $23.80 \pm 2.44$ & $15.0-23.5$ \\
Core body (spring, 2002-2003) & January & $29.57 \pm 0.77$ & $15.0-29.0$ \\
Core body (summer, 2002-2003) & February & $28.58 \pm 0.63$ & $16.0-31.0$ \\
\hline
\end{tabular}

See text for sample sizes. Graphical representation of these data is in Fig. 2.

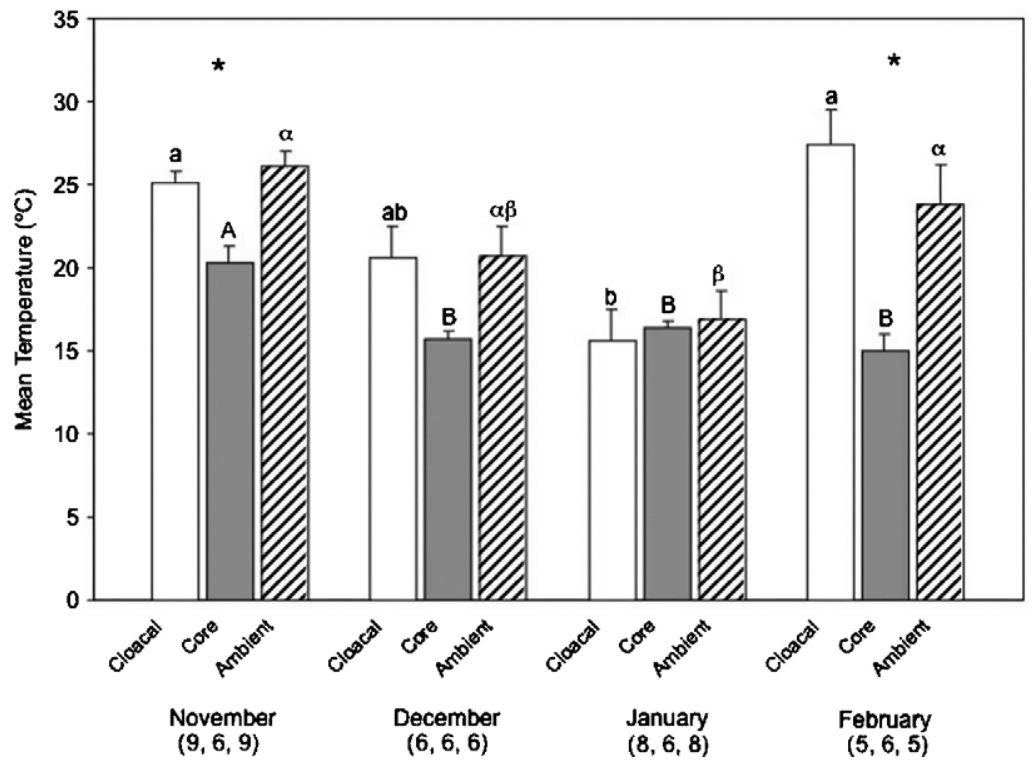

Fig. 2. Cloacal temperatures of basking males (open bars) and core body temperatures of non-basking males inside dens (gray bars) in adult Crotalus atrox during winter. Hatched bars represent ambient air temperatures. Cloacal and ambient air temperatures were obtained from 1999 to 2000 . Core body temperatures were obtained from 2002 to 2003 . Histogram bars denote non-adjusted means ( $\pm 1 \mathrm{SE}$ ). Parenthetical values denote sample sizes for cloacal, core body, and ambient air temperatures, respectively, for each sampling month. Significant differences across months for cloacal, core body, and ambient air temperatures are represented with lower-case letters, upper-case letters, and symbols, respectively. Bars with different letters or symbols within a temperature category are significantly different $(P<0.05)$. An asterisk above the bars denotes the following relationship: cloacal $=$ ambient $>$ core $(P<0.05)$. 
across months (repeated-measures ANOVA: $\mathrm{F}_{5,25}=122.9$, $P<0.0001$ ), and they were significantly higher in November than in December, January or February (SNK, $P<0.05$ ); the latter three months did not differ significantly (SNK, $P>0.05)$. Core body temperatures of non-basking subjects sampled during the winter (November-February, 20022003) were significantly lower than core body temperatures of individuals during the spring and summer (SNK, $P<0.05)$.

There was a significant difference between ambient, basking cloacal, and non-basking core body temperatures in November $\left(F_{2,22}=10.63, P=0.0006\right)$ and February $\left(F_{2,14}=13.82, \quad P=0.0005\right), \quad$ but not in December $\left(F_{2,16}=3.99, \quad P=0.04 ; \quad \alpha_{\text {adj }}=0.025\right) \quad$ and January $\left(F_{2,20}=0.17, P=0.84\right)$. In November and February, ambient and basking cloacal temperatures were significantly higher than non-basking core body temperatures (SNK, $P<0.05)$; there was no difference between ambient and basking cloacal temperatures in the winter sampling period (November-February).

Regression of body size (SVL) and cloacal temperature (dependent variable) was not significant $\left(F_{1,26}=1.19, P=0.29\right.$, $\left.R^{2}=0.04\right)$, nor was cloacal temperature and levels of plasma sex steroids (T: $F_{1,26}=0.63, P=0.44, R^{2}=0.024 ;$ DHT: $F_{1,26}=0.04, P=0.84, R^{2}=0.002 ; \mathrm{E} 2: F_{1,26}=0.10, P=0.75$, $\left.R^{2}=0.004\right)$. The minimal effect of cloacal temperatures on sex steroid levels did not vary across months (cloacal temperature $\times$ month, all steroids: $\mathrm{T}: F_{3,20}=1.84, P=0.17$; DHT: $F_{3,20}=1.08, P=0.38$; E2: $F_{3,20}=2.66, P=0.08$ ).

\section{Discussion}

We show in this study that adult male $C$. atrox from populations in southern Arizona that were sampled during the winter while basking outside of communal dens had relatively high concentrations of plasma T, DHT, and E2. These levels, furthermore, were significantly higher than those reported as basal during the active season ( $\mathrm{T}$ and DHT: May and June; E2: April-June) (Schuett et al., 2005; Taylor et al., 2004a). Thus, our initial view that these sex steroids might be at basal levels during winter was not supported.

Field studies on the common garter snake (Thamnophis sirtalis) from various parts of its expansive range in North America show that levels of circulating androgens (e.g., T) in males at the time of spring emergence are often equivalent to levels obtained in fall just prior to hibernation (Krohmer et al., 1987; Moore et al., 2000b; Clesson et al., 2002; but see Crews, 1984; Crews et al., 1984; Crews and Moore, 2005), with a relatively rapid decline to basal levels following the brief (days to several weeks) mating season. Despite the fact that determination of levels of plasma sex steroids from free-living garter snakes (e.g., Manitoba populations) during hibernation has not been possible due to their inaccessibility, comparison of levels at the time of ingress (fall) and egress (spring) suggests that they are stable throughout the period of hibernation.
In a laboratory study of the annual cycle of plasma $\mathrm{T}$ in male copperhead snakes (Agkistrodon contortrix), a North American pitviper and a close relative of $C$. atrox, levels of $T$ remained unchanged from the period just prior to forced hibernation, throughout winter, and at the time when the snakes were brought out in spring. Unlike male C. atrox in this study, male copperheads were maintained at constant cool temperatures $\left(10-15^{\circ} \mathrm{C}\right)$ and not permitted to thermoregulate (Schuett et al., 1997).

The relatively high levels of plasma sex steroids in male garter snakes and copperheads during winter might be due to a limited level of sex steroid production, but more likely metabolic clearance is sluggish or inhibited altogether due to low temperatures (Bentley, 1976; Norris, 1997; Crews and Moore, 2005). The latter view is difficult to envision as a possible explanation in male $C$. atrox, particularly given the evidence we present herein that they can remain active and have relatively high body temperatures when basking during winter (see Repp, 1998). Future studies on male C. atrox should distinguish which of these two views is operating, and include analyses of forebrain activity, such as GnRH synthesis and secretion.

Statistical comparison of absolute levels of sex steroid from different studies can be problematic for several reasons, which include differences in measurement procedures or the geographical location of the subjects. The comparisons we make herein seem reasonable given that the RIAs in this study and in Schuett et al. (2005) used similar methods and were performed in the same laboratory by the same technicians. Moreover, the snakes that were sampled during the active season by Schuett et al. (2005) were from an area just west of Phoenix, Arizona, which was at a slightly higher latitude than the sites in the winter study, but the overall habitats were nearly identical. Even if seasonal comparisons of absolute levels of sex steroids in male $C$. atrox are viewed as tentative until further work is accomplished, winter levels of plasma T, DHT, and E2 were not trivial and will thus require additional investigation regarding possible function.

Although body size (e.g., SVL and mass) and body condition (residual of the regression of body mass on SVL) are important factors in assessing sex steroid levels in reptiles (e.g., Moore et al., 2000b), including other species of rattlesnakes (Schuett et al., 2002, 2005), neither of these factors had a significant relationship to sex steroid levels across the winter months (November-February) in this study.

The concentration hierarchy of the plasma sex steroids in adult male $C$. atrox during winter was $\mathrm{T}>\mathrm{DHT}>\mathrm{E} 2$ (Fig. 1), which is the pattern that has been described in males during active season (mid-March to mid-November) (Schuett et al., 2005; Taylor et al., 2004a). This hierarchical relationship of sex steroids also has been described in freeliving adult male Mohave rattlesnakes, Crotalus scutulatus (Schuett et al., 2002). Although absolute concentrations of plasma sex steroids varied significantly over a 12-month period in male C. atrox, it appears that the hierarchy of their relative concentrations does not. The significance of 
this pattern awaits further study because there is no experimental work on the relative functions of these particular steroids in male vipers (Moore and Lindzey, 1992; Saint Girons et al., 1993; Schuett et al., 2002, 2005).

In male $C$. atrox, regression analyses of cloacal temperatures (basking snakes) and levels of T, DHT, and E2 were not significant; thus, we were unable to demonstrate a relationship between body temperatures and sex steroid concentrations. Furthermore, although we have core body temperature data on non-basking individuals (inside dens), data on steroid levels is lacking due to their inaccessibility. Accordingly, we cannot determine at this time the relationships between winter basking, body temperatures, and levels of plasma sex steroids. Because some threshold body temperature needs to be achieved to maintain the activity of testes to produce and secrete sex steroids (e.g., Aldridge, 1975; Lillywhite, 1987), it will be important to ascertain in future studies whether levels of T, DHT, and or E2 in male C. atrox during winter vary between basking and non-basking individuals. Sampling individuals under semi-natural conditions that mimic hibernation is one possible approach to circumvent the problem of inaccessibility (see Edwards and Jones, 2001a,b; Saint Girons et al., 1993).

Because ambient air temperatures during winter were not significantly different in the two different sampling periods (1999-2000 and 2002-2003), we compared cloacal temperatures of basking male $C$. atrox vs. core body temperatures of non-basking (inside dens) individuals. Cloacal temperatures were significantly greater than core body temperatures of individuals in November-December, and February (Table 1, Fig. 2). Although mean cloacal temperatures of basking males were not statistically different from ambient temperatures, both of these values were significantly greater than core body temperatures of non-basking males (inside dens) in November and February (Fig. 2). Furthermore, cloacal temperatures in February were very similar to the core body values we obtained via radiotelemetry during the active season (Table 1, Fig. 2; see Taylor et al., 2004b). Thus, although other functions might be operating, basking by male $C$. atrox outside communal dens is associated with increases in body temperatures above those experienced inside the dens.

Based on the descriptive findings of this study additional research is needed to determine whether there is a functional relationship between levels of plasma sex steroids, winter basking, and body temperatures in adult male C. atrox. One possible hypothesis to test is whether elevated body temperatures achieved by basking influences activity of the HPG-axis, such as GnRH production and steroidogenic activity of interstitial cells of the testis. Also, in future work comparing body temperatures and sex steroid levels, we suggest that core body temperatures be used instead of cloacal temperatures. Although we deem that the cloacal temperatures we obtained in this study are valuable in such comparisons, they: (a) are incomplete due to point sampling, (b) may not reflect core body temperatures, and (c) do not provide a complete profile of a subject's thermal biology (Taylor et al., 2004b). Among the best methods to obtain better temperature profiles of C. atrox in nature involves the use of surgically implanted temperature-loggers, such as iButtons (Angilletta and Krochmal, 2003). Temperature-loggers collect semi-continuous body temperatures at predetermined time intervals and have been successfully used in field studies of reptiles (Angilletta and Krochmal, 2003), including C. atrox (Taylor et al., 2004b).

Over 20 years ago, Crews (1984) and Crews et al. (1984) (see overviews by Moore and Lindzey, 1992; Crews and Moore, 2005) proposed the associated-dissociated model of reproduction, wherein the mating system of the redsided garter snake ( $T$. sirtalis parietalis) was emphasized as relatively unique among vertebrates. This was the case because, during the spring mating season, there was initial evidence from one population (Manitoba) that hormone secretion was decoupled or "dissociated" from sexual behavior (but see Krohmer et al., 1987). Despite the fact that this binary model has contributed important insights, it also has spawned a fair level of confusion (e.g., Krohmer et al., 1987; Moore et al., 2000b; Schuett, 1992; Saint Girons et al., 1993; Schuett et al., 1997, 2002; Taylor et al., 2004a). We have no doubt that a number of species seem to fit into one of the two categories of this model, but a recent body of empirical findings on other taxa appears to contradict its generality.

As discussed by Schuett and colleagues (Schuett, 1992; Schuett et al., 2002, 2005), as well as by Saint Girons et al. (1993), Taylor et al. (2004a) and Taylor and DeNardo (2005), the reproductive biology of other snake species, particularly North American pitvipers, operates simultaneously in both associated and dissociated domains. In rattlesnakes (including C. atrox) and several other viperids from temperate regions, for example, spermatogenesis occurs throughout the active season, and testis size increases in concert with sperm development. Furthermore, peak activity of spermatogenesis is associated with high levels of circulating sex steroids in late summer and early autumn, and during this period, mating occurs along with related behavior (e.g., male-male aggression). In some species, such as C. atrox (Repp, 1998; Schuett et al., 2005; Taylor and DeNardo, 2005) and C. scutulatus (Schuett et al., 2002), mating behavior occurs in a second period following a 4-month period of hibernation. As we have shown in the present study, winter levels of T, DHT, and E2 in male C. atrox were not basal when compared to levels in the active season. In the second mating season, spermatogenesis is undergoing the final stages of regression, yet the tests are large and equivalent to sizes obtained during late summer (Schuett et al., 2002) moreover, circulating concentrations of sex steroids undergo a dramatic increase, and these levels are equivalent to or greater than values from the previous mating season in late summer and autumn. This indicates that, although the machinery of spermatogenesis is regressed, the testis is not, and it remains active in endocrine function. 
In males of C. atrox and the other species, therefore, the categorical assignment of either associated or dissociated to describe their annual reproductive cycle is uninformative. Accordingly, in these cases and others, the explanatory and predictive power of the associated-dissociated model is diminished with respect to revealing robust mechanisms associated with the control and modulation of reproduction in reptiles and other vertebrates.

\section{Acknowledgments}

We are grateful for the assistance of the Schuett family (Laura, Laudon, and Emory). Chad Montgomery, Jack O'Leile, Ryan Sawby, and Don Swann provided invaluable assistance in the field. Steve Beaupre, Mike Cardwell, Harry Greene, Matthew Grober, Dave Hardy, and Randy Reiserer always made themselves available to discuss rattlesnake biology. Steve Goldberg kindly discussed with us spermatogenesis in C. atrox. Several anonymous reviewers sharpened our focus on several topics and thus improved and earlier version of this manuscript. Funding for this study was by a Research Incentive Award and a Scholarship Research Creative Activities Award (Arizona State University) to G.W.S., and a National Science Foundation Graduate Research Fellowship to E.T. Snakes were collected under Arizona Game \& Fish Department scientific collecting permits. This research was approved by the IACUC at Arizona State University (98-429R) to G.W.S. We dedicate this paper to the memory of Timothy Repp, who showed great love for the Sonoran Desert and all of its life.

\section{References}

Aldridge, R.D., 1975. Environmental control of spermatogenesis in the rattlesnake Crotalus viridis. Copeia 1975, 493-496.

Angilletta, M.J., Krochmal, A.P., 2003. The thermochron: a truly miniature and inexpensive temperature-logger. Herpetol. Rev. 34, 31-32.

Bentley, P.J., 1976. Comparative Vertebrate Endocrinology. Cambridge University Press, Cambridge, MA.

Brown, D.E., 1982. Biotic communities of the American southwest. Desert Plants $4,1-342$.

Callard, I.P., Ho, S.M., 1980. Seasonal reproductive cycles in reptiles. In: Reiter, R.J., Follett, B.K. (Eds.), Progress in Reproductive Biology: Seasonal Reproduction in Higher Vertebrates, Vol. 5. Karger, Basel, Switzerland, pp. 5-38.

Chieffi, P., D’Amato, L.C., Guarino, F., Salvatore, G., Angelini, F., 2002. $17 \beta$-Estradiol induces spermatogonial proliferation through mitogen-activated protein kinase (extracellular signal-regulated kinase 1/ 2) activity in the lizard (Podarcis s. sicula). Mol. Reprod. Dev. 61, 218-225.

Clesson, D., Bautista, A., Baleckaitis, Krohmer, R.W., 2002. Reproductive biology of male eastern garter snakes (Thamnophis sirtalis sirtalis) from a denning population in central Wisconsin. Am. Midl. Nat. 147, 376-386.

Costa, D.P., Sinervo, B., 2004. Physiological insights from animals in nature. Ann. Rev. Physiol. 66, 209-238.

Cree, A., Cockrem, J.F., Guillette Jr., L.J., 1992. Reproductive cycles of male and female tuatara (Sphenodon punctatus) on Stephens Island, New Zealand. J. Zool. 226, 199-217.

Crews, D., 1984. Gamete production, sex hormone secretion, and mating behavior uncoupled. Horm. Behav. 18, 22-28.
Crews, D., Moore, M.C., 2005. Historical contributions of research on reptiles to behavioral neuroendocrinology. Horm. Behav. 48, 294-384.

Crews, D., Camazine, B., Diamond, M., Mason, R., Tokarz, R., Garstka, W.R., 1984. Hormonal independence of courtship behavior in the male garter snake. Horm. Behav. 18, 29-41.

Drickamer, L.C., Gillie, L.L., 1998. Integrating proximate and ultimate causation in the field of vertebrate behavior: methods considerations. Am. Zool. 38, 43-58.

Duvall, D., Schuett, G.W., Arnold, S.J., 1993. Ecology and evolution of snake mating systems. In: Seigel, R., Collins, J.T. (Eds.), Snakes: Ecology and Behavior. McGraw-Hill, New York, pp. 165-200.

Edwards, A., Jones, S.M., 2001a. Changes in plasma testosterone, estrogen, and progesterone concentrations throughout the annual reproductive cycle in male viviparous blue-tongued skinks, Tiliqua nigrolutea, in Tasmania. J. Herpetol. 35, 293-299.

Edwards, A., Jones, S.M., 2001b. Changes in plasma progesterone, estrogen, and testosterone, concentrations throughout the reproductive cycle in female viviparous blue-tongued skinks, Tiliqua nigrolutea (Scincidae), in Tasmania. Gen. Comp. Endocrinol. 122, 260-269.

Feder, M.E., Bennett, A.F., Huey, R.B., 2000. Evolutionary physiology. Ann. Rev. Ecol. Syst. 31, 315-341.

Fusani, L., Canoine, V., Goymann, W., Wikelski, M., Hau, M., 2005. Difficulties and special issues associated with field research in behavioral neuroendocrinology. Horm. Behav. 48, 484-491.

Gregory, P.T., 1982. Reptilian hibernation. In: Gans, C., Pough, F.H. (Eds.), Biology of the Reptilia, Vol. 13 Physiology D. Academic Press, London, pp. 53-154.

Gregory, P.T., 1984. Communal denning in snakes. In: Seigel, R.A., Hunt, L.E., Knight, J.L., Malaret, L., Zuschlag, N.L. (Eds.), Vertebrate Ecology and Systematics: A Tribute to Henry S. Fitch. Univ. Kansas Mus. Nat. Hist. Spec. Publ. 10, pp. 57-75.

Insel, T., Fernald, R.D., 2004. How the brain processes social information: searching for the social brain. Annu. Rev. Neurosci. 27, 697-722.

Jacob, J.S., Williams, S.R., Reynolds, R.P., 1987. Reproductive activity of male Crotalus atrox and C. scutulatus (Reptilia: Viperidae) in northeastern Chihuahua, Mexico. Southwest. Nat. 32, 273-276.

Krohmer, R.W., Grassman, M., Crews, D., 1987. Annual reproductive cycle in the male red-sided garter snake, Thamnophis sirtalis parietalis: field and laboratory studies. Gen. Comp. Endocrinol. 68, 64-75.

Lance, V.A., Elsey, R.M., Butterstein, G., Trosclair, P.L., 2003. Rapid suppression of testosterone secretion after capture in male American alligators (Alligator mississppiensis). Gen. Comp. Endocrinol. 135, 217-222.

Lillywhite, H.B., 1987. Temperature, energetics, and physiological ecology. In: Seigel, R.A., Collins, J.T., Novak, S.S. (Eds.), Snakes: Ecology and Evolutionary Biology. MacMillan, New York, pp. 422-477.

McPherson, R.J., Boots, L.R., McGregor, R., Marion, K.R., 1982. Plasma steroids associated with seasonal reproductive changes in a multiclutched freshwater turtle, Sternotherus odoratus. Gen. Comp. Endocrinol. 48, 440-451.

Moore, M.C., Lindzey, J., 1992. The physiological basis of sexual behavior in male reptiles. In: Gans, C., Crews, D. (Eds.), Biology of the Reptilia, Vol. 18. The University of Chicago Press, Chicago, IL, pp. 70-113.

Moore, I.T., Lemaster, M.P., Mason, R.T., 2000a. Behavioural and hormonal responses to capture stress in the male red-spotted garter snake, Thamnophis sirtalis parietalis. Anim. Behav. 59, 529-536.

Moore, I.T., Lerner, J.P., Lerner, D.T., Mason, R.T., 2000b. Relationships between annual cycles of testosterone, corticosterone, and body condition in male red-spotted garter snakes, Thamnophis sirtalis concinnus. Physiol. Biochem. Zool. 73, 307-312.

Murdoch, W.J., Dunn, T.G., 1982. Alterations in follicular steroid hormones during the preovulatory period in the ewe. Biol. Reprod. 27, 300-307.

Norris, D.O., 1997. Vertebrate Endocrinology, third ed. Academic Press, San Diego, CA.

Norris, D.O., Jones, R.E. (Eds.), 1987. Hormones and Reproduction in Fishes, Amphibians, and Reptiles. Plenum Press, New York, pp. 355-384. 
Reinert, H.K., 1992. Radiotelemetric field studies of pitvipers: data acquisition and analysis. In: Campbell, J.A., Brodie, Jr., E.D. (Eds.), Biology of the Pitvipers. Selva, Tyler, TX, pp. 185-198.

Repp, R., 1998. Wintertime observations on five species of reptiles in the Tucson area: shelter site selections/fidelity to shelter sites/notes on behavior. Bull. Chicago Herpetol. Soc. 33, 49-56.

Romero, L.M., 2002. Seasonal changes in plasma glucocorticoid concentrations in free-living vertebrates. Gen. Comp. Endocrinol. 128, 1-24.

Rooney, A.A., Crain, D.A., Woodward, A.R., Guillette Jr., L.J., 2004. Seasonal variation in plasma sex steroid concentrations in juvenile American alligators. Gen. Comp. Endocrinol. 135, 25-34.

Saint Girons, H., Bradshaw, S.D., Bradshaw, F.J., 1993. Sexual activity and plasma levels of sex steroids in the Aspic viper Vipera aspis L. (Reptilia, Viperidae). Gen. Comp. Endocrinol. 91, 287-297.

Schuett, G.W., 1992. Is long-term sperm storage an important component of the reproductive biology of temperate pitvipers? In: Campbell, J.A., Brodie, Jr., E.D. (Eds.), Biology of the Pitvipers. Selva, Tyler, TX, pp. $169-184$.

Schuett, G.W., Harlow, H.J., Rose, J.D., Van Kirk, E.A., Murdoch, W.J., 1997. Annual cycle of plasma testosterone in male copperheads, Agkistrodon contortrix (Serpentes, Viperidae): relationship to timing of spermatogenesis, mating, and agonistic behavior. Gen. Comp. Endocrinol. $105,417-424$

Schuett, G.W., Carlisle, S.L., Holycross, A.T., Hardy Sr., D.L., Van Kirk, E.A., Murdoch, W.J., 2002. Mating system of male Mojave Rattlesnakes (Crotalus scutulatus): seasonal timing of mating, agonistic behavior, spermatogenesis, sexual segment of the kidney, and plasma sex steroids. In: Schuett, G.W., Höggren, M., Douglas, M.E., Greene, H.W. (Eds.), Biology of the Vipers. Eagle Mountain Publishing LC, Eagle Mountain, Utah, pp. 515-532.

Schuett, G.W., Grober, M.S., Van Kirk, E.A., Murdoch, W.J., 2004. Longterm sperm storage and plasma sex steroid profile of pregnancy in a western diamond-backed rattlesnake (Crotalus atrox). Herpetol. Rev. $35,328-333$.

Schuett, G.W., Hardy Sr., D.L., Greene, H.W., Earley, R.L., Grober, M.S., Van Kirk, E.A., Murdoch, W.J., 2005. Sympatric rattlesnakes with contrasting mating systems show differences in seasonal patterns of plasma sex steroids. Anim. Behav. 70, 257-266.
Sexton, O.J., Jacobson, P., Bramble, J.E., 1992. Geographic variation in some activities associated with hibernation in Neartic pitvipers. In Campbell, J.A., Brodie, Jr., E.D. (Eds.), Biology of the Pitvipers. Selva, Tyler, TX, pp. 337-345.

Shine, R., 2003. Reproductive strategies in snakes. Proc. R. Soc. London B 270, 995-1004.

Taylor, E.N., DeNardo, D.F., 2005. Reproductive ecology of western diamond-backed rattlesnakes (Crotalus atrox) in the Sonoran Desert. Copeia 2005, 152-158.

Taylor, E.N., Schuett, G.W., 2004. Effect of temperature and storage duration on the stability of steroid hormones in blood samples from western diamond-backed rattlesnakes (Crotalus atrox). Herpetol. Rev. 35, 14-17.

Taylor, E.N., DeNardo, D.F., Jennings, D.H., 2004a. Seasonal steroid hormones levels and their relation to reproduction in the western diamond-backed rattlesnake, Crotalus atrox (Serpentes: Viperidae). Gen. Comp. Endocrinol. 136, 328-337.

Taylor, E.N., DeNardo, D.F., Malaway, M.A., 2004b. A comparison between point- and semi-continuous sampling for assessing body temperature in a free-ranging ectotherm. J. Therm. Biol. 29, 91-96.

Tyrrell, C.L., Cree, A., 1998. Relationship between corticosterone concentration and season, time of day and confinement in a wild reptile (tuatara, Sphenodon punctatus). Gen. Comp. Endocrinol. 110, 97-108.

Ultsch, G.R., 1989. Ecology and physiology of hibernation and overwintering among fresh-water fishes, turtles, and snakes. Biol. Rev. 64, 435-516.

Wallen, K., Schneider, J.E. (Eds.), 2000. Reproduction in Context. MIT Press, Cambridge, MA.

Whittier, J.M., Tokarz, R.R., 1992. Physiological regulation of sexual behavior in female reptiles. In: Gans, C., Crews, D. (Eds.), Biology of the Reptilia, Vol. 18. The University of Chicago Press, Chicago, IL, pp. 24-69.

Wingfield, J.C., Jacobs, J., Hillgarth, N., 1997. Ecological constraints and the evolution of hormone-behavior interrelationships. Ann. NY Acad. Sci. 807, 22-41.

Zaidan III, F., Kreider, D.L., Beaupre, S.J., 2003. Testosterone cycles and reproductive energetics: implications for northern range limits of the cottonmouth. Copeia 2003, 231-240.

Zar, J.H., 1999. Biostatistical Analysis, fourth ed. Prentice-Hall, Upper Saddle River, NJ. 